\title{
Protective effects of dexmedetomidine on lung in rats with one-lung ventilation
}

\author{
JUNTAO WANG $^{1 *}$, XUANLONG YI ${ }^{1 *}$, LILI JIANG ${ }^{1}, \mathrm{HE} \mathrm{DONG}^{1}$, \\ WEI FENG ${ }^{1}$, SHUNTAO WANG ${ }^{2}$ and CHUNQIN CHU ${ }^{1}$
}

\author{
${ }^{1}$ Department of Anesthesiology, The Affiliated Hospital of Qingdao University, Qingdao, \\ Shandong 266000; ${ }^{2}$ Department of Breast and Thyroid Surgery, Union Hospital, Tongji Medical College, \\ Huazhong University of Science and Technology, Wuhan, Hubei 430071, P.R. China
}

Received April 23, 2018; Accepted October 26, 2018

DOI: $10.3892 /$ etm.2018.6952

\begin{abstract}
Protective effect of dexmedetomidine (DEX) on the lungs of one-lung ventilation (OLV) rat model and its effect on inflammatory factors were investigated. Ninety-two rats were selected and divided into groups A, B, C and D $(n=23)$ according to the principle of similar body weight. OLV rat model was established. Before modeling (15 min), rats in group $\mathrm{C}$ were injected with sodium chloride. Rats in group D were injected with DEX at a speed of $5 \mu \mathrm{g} / \mathrm{kg} / \mathrm{h}$. Group A rats were ventilated in both lungs for $2 \mathrm{~h}$. Rats in groups B and C $(0.9 \%$ sodium chloride injection $+\mathrm{OLV})$ and in group $\mathrm{D}(\mathrm{DEX}+\mathrm{OLV})$ were subjected to OLV for $2 \mathrm{~h}$ and bilateral ventilation for $10 \mathrm{~min}$. Concentrations of interleukin (IL)-6, IL-10 and tumor necrosis factor- $\alpha(\mathrm{TNF}-\alpha)$ in lung tissue of rats were detected by ELISA. The malondialdehyde (MDA) concentration and superoxide dismutase (SOD) activity in rat lung tissue were detected by radioimmunoassay. Wet weight (W)/dry weight (D) of lung tissue was calculated and indexes of the four groups of rats were compared. Compared with group A, IL-6, TNF- $\alpha$ and MDA concentrations and W/D of lung tissue of rats in groups B, C and D were significantly increased ( $p<0.05)$; SOD activity and IL-10 concentration were significantly decreased $(\mathrm{p}<0.01)$. Compared with groups $\mathrm{B}$ and $\mathrm{C}$, the concentrations of IL-6, TNF- $\alpha$ and W/D in rats of group D were significantly decreased $(\mathrm{p}<0.01)$, but IL-10 significantly increased $(\mathrm{p}<0.01)$.
\end{abstract}

Correspondence to: Dr Chunqin Chu, Department of Anesthesiology, The Affiliated Hospital of Qingdao University, 16 Jiangsu Road, Qingdao, Shandong 266000, P.R. China

E-mail: ue48ut@163.com

Dr Shuntao Wang, Department of Breast and Thyroid Surgery, Union Hospital, Tongji Medical College, Huazhong University of Science and Technology, 13 Hangkong Road, Wuhan, Hubei 430071, P.R. China

E-mail: wangshuntaowh@163.com

*Contributed equally

Key words: dexmedetomidine, single-lung ventilation, rat model, lung injury
Compared with groups B and C, the MDA concentration in lung tissue of rats in group D was significantly decreased $(p<0.01)$, but SOD activity significantly increased $(p<0.01)$. DEX can inhibit the production of inflammatory factors in the development and progression of pulmonary inflammation. It can inhibit lipid peroxidation, relieve pulmonary edema, and reduce lung injury after OLV, sin order to protect the lung.

\section{Introduction}

One-lung ventilation (OLV) is a commonly used machine-controlled respiratory management method in clinical thoracic surgery. OLV, as a non-physiological method, may cause non-ventilation lung collapse in patients undergoing thoracotomy. Pulmonary collapse can cause hypoxic and ischemic phenomena, and hypoxia can easily cause lung injury. If ventilated lung tidal volume is higher than double-lung ventilation, it can cause high-grade lung injury and eventually acute lung injury (ALI) $(1,2)$. During OLV process, the ratio of intrapulmonary ventilation/blood flow can be deregulated. Hypoventilation may cause hypoxia and ischemic damage and destruction of cells. In the process of restoring blood supply, it can also increase the damage of cells, cause pathological and physiological changes in the lungs, and induce ischemia-reperfusion injury, and hypoxemia followed by acute inflammatory reactions and oxidative stress reactions, causing acute injury to multiple organs throughout the body $(3,4)$. Studies have shown that prolonged OLV and mechanical stimuli resulting from surgery can lead to the activation of inflammatory cells in patients, and the release of inflammatory factors may cause increased inflammatory reactions in the lungs and increased lung injury in patients, which in turn increase the risk of postoperative death (5). Therefore, the application of effective measures for the protection of lung tissue in patients undergoing OLV open surgery will improve the prognosis of patients.

Dexmedetomidine (DEX) is an $\alpha 2$ receptor agonist that binds to $\alpha 2$ receptors and has anti-anxiety, sedative, anti-inflammatory, antioxidative and inhibition of sympathetic effects. DEX is commonly used in clinical anesthesia (6). Studies have shown that DEX can play a protective role in organ hypoxia and ischemic injury (7). However, the 
anti-inflammatory and lung protective effects of DEX-assisted anesthesia during surgery have not been elucidated. In this study, we established a rat model of lung injury induced by OLV and explored the role of DEX in OLV.

\section{Materials and methods}

Experimental animals. A total of 92 purebred inbred strain Sprague-Dawley rats (5-11 weeks, 260-310 g) were purchased from Yison BIO (Shanghai, China) [SCXK (Shanghai) 2009-0037]. Rats were raised in a clean environment with good ventilation $\left(21-26^{\circ} \mathrm{C}\right.$, humidity of $\left.51-57 \%\right)$, they were allowed to access food and water freely, and were fasted for $6 \mathrm{~h}$ before the experiments. Animal experiments were approved by the Ethics Committee of the Affiliated Hospital of Qingdao University (Qingdao, China) and the experimental procedures were in compliance with the Guidelines for the Protection and Use of Laboratory Animals of the National Institutes of Health' (8).

Main instruments, reagents, and medications. Rat ventilator was purchased from Shanghai Yuyan Instruments Co., Ltd. (Shanghai, China). Small animal physiological monitor was purchased from the STARR Life Sciences Corp. ${ }^{\mathrm{TM}}$ (Oakmont, PA, USA). DEX injection was purchased from Jiangsu Enhua Pharmaceutical Co., Ltd. (Jiangsu, China) (batch no. H20110085). Interleukin (IL)-6, IL-10 and tumor necrosis factor- $\alpha$ (TNF- $\alpha)$ detection kits were purchased from Wuhan AmyJet Scientific, Inc. (Wuhan, China). Malondialdehyde (MDA) and superoxide dismutase (SOD) were purchased from Shanghai Xueman Biotechnology Co., Ltd. (Shanghai, China).

Animal model preparation. Following the principle of similar body weight, the rats were divided into group A, B, C and D, with 23 cases in each group. According to the methods described by Pruszkowski et al (9), an OLV rat model was established. Modeling method: rats were intraperitoneally injected with $3 \%$ pentobarbital at a dose of $40 \mathrm{mg} / \mathrm{kg}$. After anesthesia, the rats were fixed in supine position and limbs were fixed. Trachea was incised and tracheal intubation was performed. Rats in group A were subjected to bilateral ventilation for $2 \mathrm{~h}$. Catheter $(\sim 3 \mathrm{~cm})$ was placed into the right main bronchus of the rats in groups $\mathrm{B}, \mathrm{C}$ and $\mathrm{D}$, and the catheter was connected to a ventilator to perform right lung OLV for $2 \mathrm{~h}$. Mechanical ventilation parameters: $\mathrm{RR}=55$ times $/ \mathrm{min}$, $\mathrm{I}: \mathrm{E}=1: 1, \mathrm{VT}=10 \mathrm{ml} / \mathrm{kg}, \mathrm{FiO}_{2} 100 \%, \mathrm{PEEP}=0$. During ventilation process, the left lobe was not opened. After replantation, the endotracheal tube was retracted to $2 \mathrm{~cm}$ of the main trachea. $\mathrm{RR}$ was adjusted to 65 times $/ \mathrm{min}$, and VT was set to $10 \mathrm{ml} / \mathrm{kg}$ for bilateral ventilation for $10 \mathrm{~min}$. Transfemoral puncture catheter was performed and connected to a physiological monitor to monitor blood pressure, oxygen saturation, and heart rate. Blood pressure was maintained at $70-130 \mathrm{mmHg}$, blood oxygen saturation was maintained at $\sim 99 \%$, and heart rate was $250-380 / \mathrm{min}$.

Experimental grouping. Before modeling (15 min), rats in group C were injected with $5 \mathrm{ml}$ of $0.9 \%$ sodium chloride. Rats in group D were injected with DEX at a speed of $5 \mu \mathrm{g} / \mathrm{kg} / \mathrm{h}$ for microinjection pump for $50 \mathrm{~min}$. Group A rats were ventilated in both lungs for $2 \mathrm{~h}$. Rats in groups B, C and D were subjected to $\mathrm{OLV}$ for $2 \mathrm{~h}$ and bilateral ventilation for $10 \mathrm{~min}$.

Observation indicators. After the rat model was established, rats were anesthetized by intraperitoneal injection of pentobarbital sodium $(45 \mathrm{mg} / \mathrm{kg})$, and the rats in each group were sacrificed by decapitation. Left lung tissue was collected, homogenized and centrifuged at $3,000 \mathrm{x}$ g for $10 \mathrm{~min}$ at $4^{\circ} \mathrm{C}$ to collect the supernatant. Concentrations of IL-6, IL-10 and TNF- $\alpha$ in the lung tissue of rats were detected by ELISA double-antibody sandwich method. MDA concentration and SOD activity in the lung tissue of rats were detected by radioimmunoassay (Beyotime Institute of Biotechnology, Shanghai, China), and the detection scheme was carried out according to the manufacturer's instructions. The right lung tissue was taken and washed with physiological saline at $4^{\circ} \mathrm{C}$, and liquid was absorbed using filter paper. Lung tissue wet weight (W) was weighed, and the lung tissue dry weight (D) was measured after being placed in a $70 \%$ electric oven for $24 \mathrm{~h}$ to calculate the W/D of the lung tissue.

Statistical methods. SPSS 19.0 [Yiyun (Shanghai) Information Technology Co., Ltd., Shanghai, China] was used for statistical analysis. Measured data were expressed as mean \pm standard deviation (SD). Chi-square test was used for comparisons of count data. Comparisons among multiple groups were performed by one-way analysis of variance, followed by LSD-t post hoc test. $\mathrm{P}<0.05$ was considered to indicate a statistically significant difference.

\section{Results}

General information of the four groups of rats. A rat in each group $\mathrm{C}$ and $\mathrm{D}$ died due to anesthesia and the success rate was 95.65\% (22/23). Rats in both groups A and B were successfully modeled. There was no significant difference in sex, age, body weight, indoor temperature and indoor humidity among the four groups ( $>>0.05)$ (Table I).

IL-6 concentration in lung tissue of rats. The concentration of IL-6 in lung tissue of rats in groups A, B, C and D was $43.63 \pm 10.62,94.34 \pm 18.45,97.58 \pm 16.17$ and $63.41 \pm 11.54 \mu \mathrm{g} / 1$, respectively. Compared with group A, IL-6 concentration in the lung tissue of rats in groups $\mathrm{B}, \mathrm{C}$ and $\mathrm{D}$ was significantly increased $(t=11.420, p<0.001 ; t=13.290, p<0.001 ; t=5.987$, $\mathrm{p}<0.001)$. Compared with groups B and C, the L-6 concentration in group $\mathrm{D}$ was significantly decreased $(\mathrm{t}=6.706, \mathrm{p}<0.001$; $\mathrm{t}=8.068, \mathrm{p}<0.001)$. There was no significant difference in the concentration of IL- 6 between groups B and C $(t=0.625$, $\mathrm{p}=0.535)$ (Fig. 1).

Concentration of IL-10 in lung tissue of rats. The concentration of IL-10 in the lungs of rats in groups A, B, C and D was $69.52 \pm 8.41,41.63 \pm 8.02,43.18 \pm 7.64$ and $53.45 \pm 7.01 \mu \mathrm{g} / 1$, respectively. Compared with group A, IL-10 concentration in the lung tissue of rats in groups B, C and D was significantly decreased $(t=11.510, p<0.001 ; t=10.980, p<0.001 ; t=6.946$, $\mathrm{p}<0.001)$. Compared with groups B and C, the IL-10 concentration in group D was significantly increased $(t=5.254$, 
Table I. General information of the four groups of rats [n (\%)] (mean \pm SD).

\begin{tabular}{lrrrrrr}
\hline Items & $\mathrm{A}(\mathrm{n}=23)$ & $\mathrm{B}(\mathrm{n}=23)$ & $\mathrm{C}(\mathrm{n}=22)$ & $\mathrm{D}(\mathrm{n}=22)$ & $\chi^{2}$ & P-value \\
\hline Sex & & & & & 2.391 & 0.492 \\
$\quad$ Male & $15(65.22)$ & $11(47.83)$ & $13(59.09)$ & $10(45.45)$ & & \\
Female & $8(34.78)$ & $12(52.17)$ & $9(40.91)$ & $12(54.55)$ & & 0.831 \\
Indoor temperature $\left({ }^{\circ} \mathrm{C}\right)$ & $23.98 \pm 1.39$ & $24.03 \pm 1.12$ & $23.83 \pm 1.27$ & $24.18 \pm 1.22$ & 0.291 & 0.260 \\
Indoor humidity $(\%)$ & $53.87 \pm 1.33$ & $54.42 \pm 1.26$ & $54.31 \pm 1.02$ & $54.51 \pm 0.98$ & 1.360 & \\
\hline
\end{tabular}

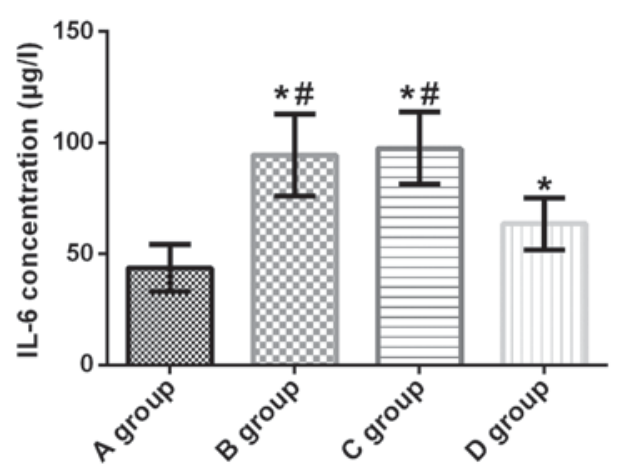

Figure 1. Comparison of lung tissue IL-6 concentration among four groups. ELISA double-antibody sandwich assay showed that the IL- 6 concentration in the lungs of rats in groups B, C and D was significantly higher than that in group A. Compared with group B and C, IL-6 concentration in the lungs of rats in group $\mathrm{D}$ was significantly decreased. There was no significant difference in concentration of IL-6 between groups $\mathrm{B}$ and $\mathrm{C}(\mathrm{t}=0.625, \mathrm{p}=0.535)$ ${ }^{*} \mathrm{P}<0.001$, compared with group $\mathrm{A} ;{ }^{\#} \mathrm{p}<0.001$, compared with group D. IL, interleukin.

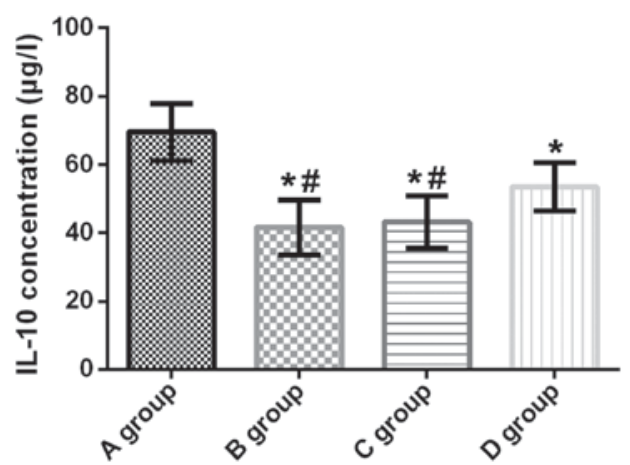

Figure 2. Comparison of lung tissue IL-10 concentration among four groups. ELISA double-antibody sandwich assay showed that, compared with group A, IL-10 concentration in the lung tissue of rats in groups B, $\mathrm{C}$ and D was significantly decreased. Compared with groups B and C, IL-10 concentration in the lungs of rats in group D increased significantly. There was no significant difference in IL-10 concentration between groups B and C $(\mathrm{t}=0.663, \mathrm{p}=0.510) .{ }^{*} \mathrm{P}<0.001$, compared with group $\mathrm{A} ;{ }^{*} \mathrm{p}<0.001$, compared with group D. IL, interleukin.

$\mathrm{p}<0.001 ; \mathrm{t}=4.646, \mathrm{p}<0.001)$. There was no significant difference in IL-10 concentration between groups B and C $(\mathrm{t}=0.663$, $\mathrm{p}=0.510)$ (Fig. 2).

TNF- $\alpha$ concentration in lung tissue of rats. The concentration of TNF- $\alpha$ in the lung tissue of rats in groups A, B, C and D was $30.74 \pm 6.41,63.54 \pm 13.58,66.79 \pm 13.86$, and $47.21 \pm 8.97 \mu \mathrm{g} / 1$,

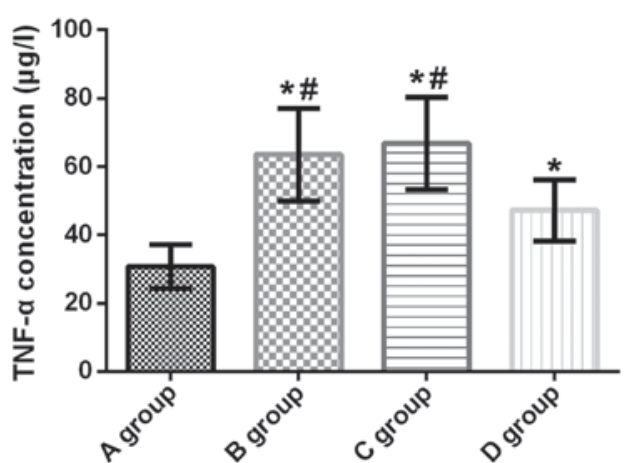

Figure 3. Comparison of TNF- $\alpha$ concentration among four groups. ELISA double-antibody sandwich assay showed that, compared with group A, TNF- $\alpha$ concentration in lung tissue of rats in groups B, C and D was significantly increased. Compared with groups $\mathrm{B}$ and $\mathrm{C}$, the concentration of TNF- $\alpha$ in lung tissue of rats in group D was significantly decreased. There was no significant difference in the concentration of TNF- $\alpha$ between groups $\mathrm{B}$ and $\mathrm{C}$ $(\mathrm{t}=0.794, \mathrm{p}=0.431) .{ }^{*} \mathrm{P}<0.001$, compared with group $\mathrm{A} ;{ }^{*} \mathrm{p}<0.001$, compared with group D. TNF- $\alpha$, tumor necrosis factor- $\alpha$.

respectively. Compared with group $\mathrm{A}$, the concentration of TNF- $\alpha$ in the lung tissue of rats in groups B, C and D was significantly increased $(t=10.460, p<0.001 ; t=11.280$, $\mathrm{p}<0.001 ; \mathrm{t}=7.111, \mathrm{p}<0.001)$. Compared with groups $\mathrm{B}$ and $\mathrm{C}$, the concentration of TNF- $\alpha$ in group D was significantly decreased $(\mathrm{t}=5.563, \mathrm{p}<0.001 ; \mathrm{t}=4.725, \mathrm{p}<0.001)$. There was no significant difference in the concentration of TNF- $\alpha$ between groups $\mathrm{B}$ and $\mathrm{C}(\mathrm{t}=0.794$, $\mathrm{p}=0.431)$ (Fig. 3 ).

MDA concentration in lung tissue of rats. MDA concentration in the lung tissue of rats in groups A, B, C and D was $3.25 \pm 1.18,5.21 \pm 1.56,5.46 \pm 1.63$, and $4.26 \pm 1.28 \mathrm{nmol} / \mathrm{ml}$, respectively. Compared with group $\mathrm{A}, \mathrm{MDA}$ concentration in the lung tissue of rats in groups B, C and D was significantly increased $(\mathrm{t}=4.767, \mathrm{p}<0.001 ; \mathrm{t}=5.227, \mathrm{p}<0.001 ; \mathrm{t}=2.754$, $\mathrm{p}=0.008)$. Compared with groups $\mathrm{B}$ and $\mathrm{C}$, the MDA concentration in group D was significantly decreased $(t=2.228$, $\mathrm{p}=0.031 ; \mathrm{t}=2.716, \mathrm{p}=0.009)$. There was no significant difference in the concentration of MDA between groups $\mathrm{B}$ and $\mathrm{C}$ $(\mathrm{t}=0.525, \mathrm{p}=0.601)$ (Fig. 4).

SOD activity in lung tissue of rats. SOD activity in lung tissue of rats in groups A, B, C and D was $85.63 \pm 9.64,68.14 \pm 8.06$, $66.46 \pm 7.24$ and $79.72 \pm 8.77 \mathrm{U} / \mathrm{ml}$, respectively. Compared with group A, SOD activity in groups B, C and D was significantly decreased $(t=6.675, p<0.001 ; t=7.516, p<0.001$; $\mathrm{t}=2.148, \mathrm{p}=0.037$ ). Compared with groups $\mathrm{B}$ and $\mathrm{C}$, the SOD 


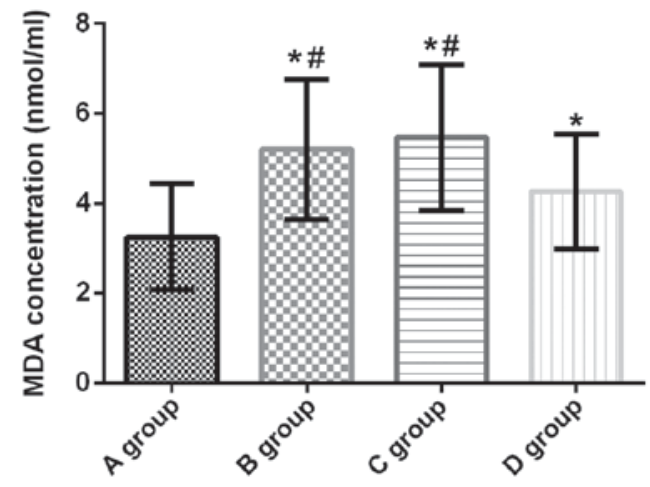

Figure 4. Comparison of MDA concentration in lung tissue of rats in four groups. Radioimmunoassay showed that, compared with group A, MDA concentration in lung tissue of rats in groups B, C and D was significantly increased. Compared with groups $\mathrm{B}$ and $\mathrm{C}$, the MDA concentration in lung tissue of rats in group D was significantly decreased. There was no significant difference in concentration of MDA between groups $\mathrm{B}$ and $\mathrm{C}(\mathrm{t}=0.525$, $\mathrm{p}=0.601) .{ }^{*} \mathrm{P}<0.01$, compared with group $\mathrm{A} ;{ }^{\#} \mathrm{p}<0.05$, compared with group $\mathrm{D}$. MDA, malondialdehyde.

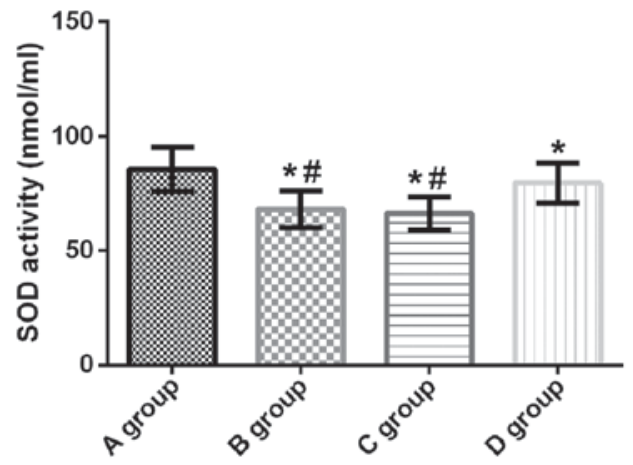

Figure 5. Comparison of SOD activity in lung tissue of rats in four groups. Radioimmunoassay showed that, compared with group A, SOD activity in lung tissue of rats in groups B, C and D was significantly decreased. Compared with groups B and C, the SOD activity in lung tissue of rats in group D was significantly increased. There was no significant difference in SOD activity between groups $\mathrm{B}$ and $\mathrm{C}(\mathrm{t}=0.734, \mathrm{p}=0.466) .{ }^{*} \mathrm{P}<0.05$, compared with group $\mathrm{A} ;{ }^{\#} \mathrm{p}<0.001$, compared with group D. SOD, superoxide dismutase.

activity in group D was significantly increased $(t=4.615$, $\mathrm{p}<0.001 ; \mathrm{t}=5.469, \mathrm{p}<0.001)$. There was no significant difference in SOD activity between groups B and C $(t=0.734$, $\mathrm{p}=0.466)$ (Fig. 5).

W/D of lung tissue of rats in all four groups. W/D of lung tissues of rats in groups A, B, C and D was 2.26 \pm 1.09 , $5.13 \pm 1.48,5.42 \pm 1.57$ and $3.65 \pm 1.31$, respectively. Compared with group A, W/D in lung tissue of groups B, C and D was significantly increased $(\mathrm{t}=7.488, \mathrm{p}<0.001 ; \mathrm{t}=7.873, \mathrm{p}<0.001$; $\mathrm{t}=3.876, \mathrm{p}=0.037)$. Compared with groups $\mathrm{B}$ and $\mathrm{C}$, the $\mathrm{W} / \mathrm{D}$ in group D was significantly decreased $(\mathrm{t}=3.546, \mathrm{p}=0.001$; $\mathrm{t}=4.060, \mathrm{p}<0.001)$. There was no significant difference in lung tissue W/D between groups $\mathrm{B}$ and $\mathrm{C}(\mathrm{t}=0.637, \mathrm{p}=0.527)$ (Fig. 6).

\section{Discussion}

OLV is the use of single- or double-lumen endotracheal intubation to open the lungs of patients with open chest. The

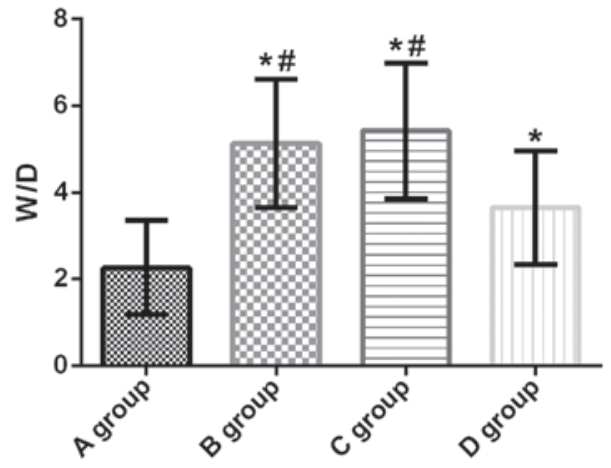

Figure 6. Comparison of lung tissue W/D among four groups. Compared with group A, W/D of lung tissue if rats in groups B, C and D was significantly increased. Compared with groups $\mathrm{B}$ and $\mathrm{C}$, the W/D ratio of lung tissue of rats in group $\mathrm{D}$ was significantly decreased. There was no significant difference in lung tissue $\mathrm{W} / \mathrm{D}$ between groups $\mathrm{B}$ and $\mathrm{C}(\mathrm{t}=0.637, \mathrm{p}=0.527) .{ }^{*} \mathrm{P}<0.05$, compared with group $\mathrm{A} ;{ }^{\#} \mathrm{p}<0.05$, compared with group $\mathrm{D}$. W, wet weight; $\mathrm{D}$, dry weight.

purpose of OLV is to obtain enough surgical vision, in order to reduce the ipsilateral lung traction, improve the clarity of the lungs, and separate the lungs to avoid effects of cancer cells and secretions from the affected lung on the healthy one (10). However, although OLV brings convenience to the operation, it may also cause lung injury of different severity. OLV may not only cause ALI, but also affect other organs, resulting in their functional disorder and affecting patients' prognosis and survival rate (11). OLV can also cause severe inflammatory reactions in the body. Excessive inflammatory response to the lungs is a progressive process of injury that can progress from ALI to systemic inflammatory response syndrome and multiple organ dysfunction syndrome (12). Studies have shown that the mortality rate from intra- and postoperative cardiac surgery caused by ALI is $3 \%$ (13). Therefore, reducing the OLV inflammatory response and lung injury has important clinical significance.

DEX is a highly selective $\alpha 2$ adrenoceptor agonist. Sedative effect of DEX is achieved by its high affinity for $\alpha 2$ distributed in the central nervous system. $\alpha 2$ is mainly distributed in locus coeruleus in the brain and plays an important role in regulating awakening and sleeping, and it can also inhibit the central sympathetic activity and reduce the release of inflammatory mediators (14). Abnormal upregulation of the proinflammatory mediators of the lungs and neutrophil infiltration can all lead to inflammatory reactions in the body, resulting in inflammatory factors that cause tissue damage and lung injury. Inflammatory response is the main cause of lung injury (15). Concentrations of IL-6, IL-10, and TNF- $\alpha$ reflect the severity of inflammation in the body and are important inflammatory factors $(16,17)$. IL-6 plays an important role in the body's immune and stress response, and has both pro- and anti-inflammatory effects. When the body is stimulated by external factors, the concentration of circulating IL- 6 can be gradually increased (18). IL-10 has a strong inhibitory effect on the production of pro-inflammatory cytokines, and is a potent inhibitory cytokine to protect the body from inflammation (19). TNF- $\alpha$ is a start factor in ALI, it plays an initial role in the development and progression of inflammatory reactions, and has immunomodulatory and anti-infective effects (20). 
Akdis et al (21) have shown that IL-10 can inhibit the release of IL-6 and TNF- $\alpha$ from monocytes and increase the level of TNF- $\alpha$ receptor, thus reducing the adhesion of white blood cells to vascular endothelial cells, inhibiting the expression of endothelial cell adhesion factors and reducing lung injury. The results of this study revealed that compared with group A, the concentrations of IL- 6 and TNF- $\alpha$ in the lungs of rats in groups B, C and D were significantly increased, and the concentration of IL-10 significantly decreased; compared with groups B and C, the concentrations of IL-6 and TNF- $\alpha$ in the lungs of rats in group D were significantly decreased, but the concentration of IL-10 was significantly increased. It is suggested that the application of DEX can reduce the inflammatory reaction in the lung and play a protective role during OLV ventilation. We speculate that DEX can control the inflammatory response by inhibiting macrophage hyper-responsiveness and protecting macrophage activity (22). Tan et al (23) have also reported that DEX can reduce the severity of inflammation and the incidence of lung injury in OLV in sepsis rats, and it protects the lungs by inhibiting the release of inflammatory factors.

OLV can cause inflammation in the lungs. Prolonged infiltration of inflammatory factors can lead to thickening of the lung parenchyma and significant congestion, causing pulmonary edema. Lung tissue W/D is an important indicator of lung water content. Changes in W/D ratio reflect lung edema and degree of lung injury (24). During OLV, occurrence of unilateral pulmonary atrophy will lead to ischemia, hypoxia, and increased oxygen-free radical production and strengthened scavenging ability in lung tissue. Reperfusion may occur in the atrophic lung tissue, and during this process, excessive oxygen-free radicals will be generated, which can induce lipid peroxidation and the formation of lipid peroxides (25). Abnormal increase in the concentration of MDA indicates strong lipid peroxidation and severe damage to the mitochondrial and cell membrane (26). SOD is the scavenger of oxygen-free radicals whose activity reflects the antioxidant capacity. Thus, changes in MDA concentration and SOD activity reflect the degree of lung injury (27). The results of this study showed that compared with group A, MDA concentration and W/D in lung tissue of rats in groups B, $\mathrm{C}$ and D were significantly increased, but SOD activity was significantly decreased. Compared with groups B and C, MDA concentration and W/D in group $\mathrm{D}$ were significantly decreased, but SOD activity was significantly increased, suggesting that DEX could interfere with oxygen-free radicals and inhibit lipid peroxidation, and can protect the lung by inhibiting the release of inflammatory factors and relieving pulmonary edema. Shen et al (28) have also shown that the protective effect of DEX on myocardium is mainly achieved by free radical scavenging and antioxidative activities.

In this study, the rats were all screened strictly. No difference in sex, age, body weight, indoor temperature and indoor humidity was found among all four groups, indicating the high reliability of our data. The establishment of OLV model in rats is simple and of low cost with favorable use value. However, there are still some limitations. Pathogenesis of lung injury in OLV rat model was not investigated and clinical application of DEX was not elucidated in this study. Therefore, we hope that in the next study, we will be able to select the research objects in clinic and study in depth the pathogenesis of lung injury caused by OLV, in order to further confirm the results of the present study.

In summary, DEX can inhibit the production of inflammatory factors in the development and progress of pulmonary inflammation and lipid peroxidation, relieve pulmonary edema and reduce lung injury after OLV to protect the lung.

\section{Acknowledgements}

Not applicable.

\section{Funding}

No funding was received.

\section{Availability of data and materials}

The datasets used and/or analyzed during the present study are available from the corresponding author on reasonable request.

\section{Authors' contributions}

JW and XY conceived and designed the study and assisted with the animal model preparation. LJ and HD were responsible for ELISA. WF and CC performed the radioimmunoassay. JW, XY and SW contributed to the statistical analysis. All authors read and approved the final manuscript.

\section{Ethics approval and consent to participate}

The study was approved by the Ethics Committee of the Affiliated Hospital of Qingdao University (Qingdao, China).

\section{Patient consent for publication}

Not applicable.

\section{Competing interests}

The authors declare that they have no competing interests.

\section{References}

1. Lu Y, Dai W, Zong Z, Xiao Y, Wu D, Liu X and Chun Wong GT: Bronchial blocker versus left double-lumen endotracheal tube for one-lung ventilation in right video-assisted thoracoscopic surgery. J Cardiothorac Vasc Anesth 32: 297-301, 2018.

2. El Tahan MR, Pasin L, Marczin N and Landoni G: Impact of low tidal volumes during one-lung ventilation. A meta-analysis of randomized controlled trials. J Cardiothorac Vasc Anesth 31: 1767-1773, 2017.

3. Murphy E and Shelley B: Response to: 'Postoperative pulmonary complications, pulmonary and systemic inflammatory responses after lung resection surgery with prolonged one-lung ventilation. Randomised controlled trial comparing intravenous and inhalational anaesthesia'. Br J Anaesth 120: 411-412, 2018.

4. Xu Z, Gu L, Bian Q, Li P, Wang L, Zhang J and Qian Y: Oxygenation, inflammatory response and lung injury during one lung ventilation in rabbits using inspired oxygen fraction of 0.6 vs. 1.0. J Biomed Res 31: 56-64, 2016.

5. de la Gala F, Piñeiro P, Reyes A, Vara E, Olmedilla L, Cruz P and Garutti I: Postoperative pulmonary complications, pulmonary and systemic inflammatory responses after lung resection surgery with prolonged one-lung ventilation. Randomized controlled trial comparing intravenous and inhalational anaesthesia. $\mathrm{Br} \mathrm{J}$ Anaesth 119: 655-663, 2017. 
6. Mahmoud M, Ishman SL, McConnell K, Fleck R, Shott S, Mylavarapu G, Gutmark E, Zou Y, Szczesniak R and Amin RS: Upper airway reflexes are preserved during dexmedetomidine sedation in children with Down syndrome and obstructive sleep apnea. J Clin Sleep Med 13: 721-727, 2017.

7. Wang SL, Duan L, Xia B, Liu Z, Wang Y and Wang GM: Dexmedetomidine preconditioning plays a neuroprotective

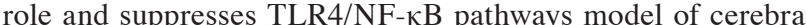
ischemia reperfusion. Biomed Pharmacother 93: 1337-1342, 2017

8. Harriss DJ, Macsween A and Atkinson G: Standards for ethics in sport and exercise science research: 2018 Update. Int J Sports Med 38: 1126-1131, 2017.

9. Pruszkowski O, Dalibon N, Moutafis M, Jugan E, Law-Koune JD, Laloë PA and Fischler M: Effects of propofol vs. sevoflurane on arterial oxygenation during one-lung ventilation. Br J Anaesth 98 539-544, 2007.

10. Clayton-Smith A, Bennett K, Alston RP, Adams G, Brown G Hawthorne T, Hu M, Sinclair A and Tan J: A Comparison of the efficacy and adverse effects of double-lumen endobronchial tubes and bronchial blockers in thoracic surgery: A systematic review and meta-analysis of randomized controlled trials. J Cardiothorac Vasc Anesth 29: 955-966, 2015.

11. Lohser J and Slinger P: Lung injury after one-lung ventilation: A review of the pathophysiologic mechanisms affecting the ventilated and the collapsed lung. Anesth Analg 121: 302-318, 2015.

12. Blank RS, Colquhoun DA, Durieux ME, Kozower BD, McMurry TL, Bender SP and Naik BI: Management of one-lung ventilation: Impact of tidal volume on complications after thoracic surgery. Anesthesiology 124: 1286-1295, 2016.

13. Primieri $\mathrm{P}$, Ancona $\mathrm{P}$ and Gualtieri E: Unusual airways management during one-lung ventilation in thoracic surgery. Saudi J Anaesth 11: 225-227, 2017.

14. Mantz J, Josserand J and Hamada S: Dexmedetomidine: New insights. Eur J Anaesthesiol 28: 3-6, 2011.

15. Iwata $M$, Inoue $S$, Kawaguchi $M$, Takahama M, Tojo $T$, Taniguchi $S$ and Furuya H: Jugular bulb venous oxygen saturation during one-lung ventilation under sevoflurane- or propofol-based anesthesia for lung surgery. J Cardiothorac Vasc Anesth 22: 71-76, 2008.

16. Aisiku IP, Yamal JM, Doshi P, Benoit JS, Gopinath S, Goodman JC and Robertson CS: Plasma cytokines IL-6, IL-8, and IL-10 are associated with the development of acute respiratory distress syndrome in patients with severe traumatic brain injury. Crit Care 20: 288, 2016.

17. Huang SR, Ma AY, Liu Y and Qu Y: Effects of inflammatory factors including plasma tumor necrosis factor- $\alpha$ in the clinical treatment of acute respiratory distress syndrome. Oncol Lett 13 : 5016-5020, 2017.
18. Heink S, Yogev N, Garbers C, Herwerth M, Aly L, Gasperi C, Husterer V, Croxford AL, Möller-Hackbarth K, Bartsch HS, et al: Trans-presentation of IL- 6 by dendritic cells is required for the priming of pathogenic TH17 cells. Nat Immunol 18: 74-85, 2017.

19. Ip WKE, Hoshi N, Shouval DS, Snapper S and Medzhitov R: Anti-inflammatory effect of IL-10 mediated by metabolic reprogramming of macrophages. Science 356: 513-519, 2017.

20. Choi ST, Kang EJ, Ha YJ and Song JS: Levels of plasma-soluble triggering receptor expressed on myeloid cells-1 (sTREM-1) are correlated with disease activity in rheumatoid arthritis. J Rheumatol 39: 933-938, 2012.

21. Akdis M, Aab A, Altunbulakli C, Azkur K, Costa RA, Crameri R, Duan S, Eiwegger T, Eljaszewicz A, Ferstl R, et al: Interleukins (from IL-1 to IL-38), interferons, transforming growth factor $\beta$, and TNF- $\alpha$ : Receptors, functions, and roles in diseases. J Allergy Clin Immunol 138: 984-1010, 2016.

22. Kuru S, Bozkirli OB, Barlas AM, Duymus ME, Senes M, Yumusak N, Yilmaz C and Kismet K: The preventive effect of dexmedetomidine against postoperative intra-abdominal adhesions in rats. Int Surg 100: 87-95, 2015.

23. Tan F, Chen Y, Yuan D, Gong C, Li X and Zhou S: Dexmedetomidine protects against acute kidney injury through downregulating inflammatory reactions in endotoxemia rats. Biomed Rep 3: 365-370, 2015.

24. Jiang W, Luo F, Lu Q, Liu J, Li P, Wang X, Fu Y, Hao K, Yan T and Ding X: The protective effect of Trillin LPS-induced acute lung injury by the regulations of inflammation and oxidative state. Chem Biol Interact 243: 127-134, 2016.

25. Heerdt PM and Stowe DF: Single-lung ventilation and oxidative stress: A different perspective on a common practice. Curr Opin Anaesthesiol 30: 42-49, 2017.

26. Tsikas D: Assessment of lipid peroxidation by measuring malondialdehyde (MDA) and relatives in biological samples: Analytical and biological challenges. Anal Biochem 524: 13-30, 2017.

27. Fan Z, Yao J, Li Y, Hu X, Shao H and Tian X: Anti-inflammatory and antioxidant effects of curcumin on acute lung injury in a rodent model of intestinal ischemia reperfusion by inhibiting the pathway of NF-кB. Int J Clin Exp Pathol 8: 3451-3459, 2015.

28. Shen J, Fu G, Jiang L, Xu J, Li L and Fu G: Effect of dexmedetomidine pretreatment on lung injury following intestinal ischemia-reperfusion. Exp Ther Med 6: 1359-1364, 2013.

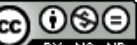

This work is licensed under a Creative Common Attribution-NonCommercial-NoDerivatives 4.0 International (CC BY-NC-ND 4.0) License. 